Research Article

\title{
KİLİKYA-ADANA -İSKENDERUN HAVZALARI'NIN PLİYO-KUVATERNER SEDİMAN DAĞILIMLARI
}

\author{
Canan ÇİFTÇi 1* ${ }^{*}$ Mahmut OKYAR ${ }^{1}$
}

${ }^{1}$ Süleyman Demirel Üniversitesi, Mühendislik Fakültesi, Jeofizik Mühendisliği Bölümü, Isparta, Türkiye

\begin{tabular}{ll}
\hline Anahtar Kelimeler & Öz \\
\hline Doğu Akdeniz, & Kilikya-Adana ve İskenderun Havzaları Afrika-Avrasya Levhalarının çarpışma zonu \\
Sismik Stratigrafi, & boyunca gelişen Neojen depolanma alanlarıdır. Doğal yapısından dolayı bu havzalar, \\
Pliyo-Kuvaterner. & geçmişten günümüze birçok jeolojik ve jeofizik çalışmaya konu olmuştur. Bu \\
& çalışmada, Pliyo-Kuvaterner zamanında biriken sediman dağılımları Türkiye \\
& Petrolleri Anonim Ortaklığı'ndan izinle temin edilen sismik yansıma profillerinin \\
& yorumlanmasıyla elde edilmiştir. Kalınlık haritası önceki çalışmalarda kullanılan \\
& $1700 \mathrm{~m} / \mathrm{sn}$ 'lik ortalama hız ile hesaplanmıştır. Yorumlamalar sonucunda, Pliyo- \\
& Kuvaterner çökellerin kalınlık değerlerinin 0-2763 m arasında değiştiği \\
& saptanmıştır. En yüksek kalınlık değerleri İskenderun Havzası'nın denizel \\
& kesiminde, Asi Nehri açıklarında 2250 m, Yumurtalık önlerinde 2763 m ve Kilikya \\
& Havzası'nın orta kesiminde $2050 \mathrm{~m}$ olarak elde edilmiștir. \\
\hline
\end{tabular}

\section{THE DISTRIBUTIONS OF PLIO-QUATERNARY SEDIMENT IN CILICIA BASIN}

Keywords Seismic Stratigraphy, Plio-Quaternary.

\begin{abstract}
The Cilicia-Adana and İskenderun basins are the Neogene depocenters developed along the Africa-Eurasia plate convergence zone. From past to present these basins have been subject of numerous geological and geophysical studies, due to their natural structure. In this study, the distributions of sediments accumulated during the Plio-Quaternary in the basin were interpreted from the seismic reflection data that obtained with permission from the Turkish Petroleum Corporation. Thickness map was prepared with the average velocity of $1700 \mathrm{~m} / \mathrm{s}$ based on previous studies. According to the interpretation results, the thickness of Plio-Quaternary sediments in the basin ranges from 0 to $2763 \mathrm{~m}$. The highest thickness values are obtained as $2250 \mathrm{~m}$ in the onshore of Iskenderun Basin, offshore of Asi River, $2763 \mathrm{~m}$ in coast of Yumurtalık and $2050 \mathrm{~m}$ in the centre of Cilicia Basin.
\end{abstract}

\section{Alıntı / Cite}

Çiftçi, C., Okyar, M., (2019). Kilikya-Adana-İskenderun Havzalari'nın Pliyo-Kuvaterner Sediman Dağılımları, Mühendislik Bilimleri ve Tasarım Dergisi, 7(1), 40-45.

\begin{tabular}{l|l|l}
\hline Yazar Kimliği / Author ID (ORCID Number) & \multicolumn{3}{|l}{ Makale Süreci / Article Process } \\
\hline C. Çiftçi, 0000-0002-7736-1192 & Başvuru Tarihi / Submission Date & 05.10 .2018 \\
M. Okyar, 0000-0002-7820-7496 & Revizyon Tarihi / Revision Date & 05.11 .2018 \\
& Kabul Tarihi / Accepted Date & 06.11 .2018 \\
& Yayım Tarihi / Published Date & 25.03 .2019 \\
\hline
\end{tabular}

\section{Giriş}

Geç Triyas dönemine ait küçük bir okyanus havzası olan Doğu Akdeniz (Robertson ve Dixon, 1984; Robertson vd., 1991), doğal yapısı gereği geçmişten günümüze değin birçok araştırmaya konu olmuştur.

Doğu Akdeniz'de bu önemli konumda yer alan çalışma alanı, yaklaşık olarak $36^{\circ}-37,5^{\circ} \mathrm{K}$ enlemleri ile $33,5^{\circ}$ $36,5^{\circ} \mathrm{D}$ boylamları arasında yer almakta, Adana-
Kilikya-İskenderun Havza Karmaşığı'nı kapsamaktadır (Şekil 1). Adana-Kilikya-İskenderun Havza Karmaşığı, Anadolu Levhası'nın güney kıyısında yer alan temel çökel depolanma merkezlerindendir. Misis-Girne Bindirme Kuşağl, Kıbrıs ve Türkiye arasındaki denizel bölgeyi kendi içinde batıda Kilikya ve doğuda İskenderun olarak iki havzaya ayırmaktadır. Adana Havzası, Kilikya ve İskenderun Havzalarının karadaki uzantısını temsil etmektedir. Kilikya-Adana Havza Karmașı̆̆ı, güneyde

\footnotetext{
* ilgili yazar/ Corresponding author: canancaa@gmail.com, +90-246-211-1358
} 
Kıbrıs Yayı, doğu ve güneydoğuda Misis-Girne Bindirme Kuşağı ile kuzey ve kuzeybatıda ise Türkiye'nin güneyindeki Toros Dağları arasında kalmaktadır. İskenderun Havzası ise Anadolu'nun güneyinde, Doğu Akdeniz'in kuzeydoğusunda, doğuda Amanos ve batıda Misis Dağlarının arasında bulunmaktadır.

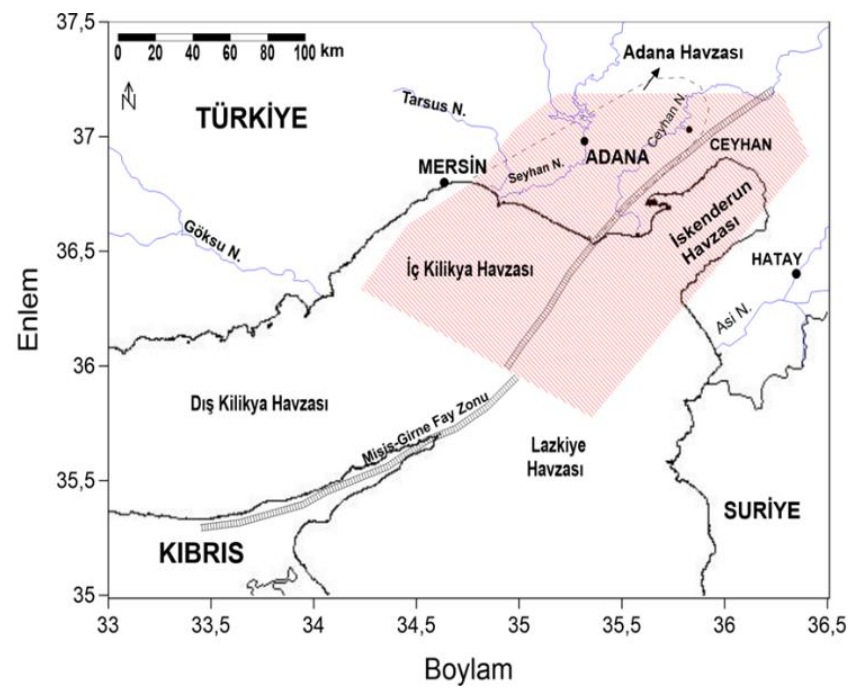

Şekil1. Çalışma alanının yer bulduru haritası

Dewey vd. (1986)'ne göre, Adana-Kilikya-İskenderun Havza Karmaşığı, sol yanal atımlı Doğu Anadolu Transform Fayı'ndan ayrılan bir seri kol üzerindeki çek-ayır havzalarıdır (Ergün vd., 1995). Söz konusu havzalar, Kıbrıs Yayı, Bitlis Bindirme Kușağı ve Doğu Anadolu Fay Zonu'nun üçlü eklem (triple junction) etkisine maruz kalmasından dolayı, oldukça önemli bir konumda bulunmaktadır.

Doğu Akdeniz'e ait birçok çalıșma yapılmıștır. Ancak, hem kara hem de deniz tarafının derin jeolojik ve sismotektonik özelliklerini inceleyen çalışmalar oldukça azdır. Neojen ve Kuvaterner yaşlı çökelleri içeren Kilikya-Adana Havzası yaklaşık olarak 1000 yılda 0.38 m'lik çökelme hızına sahiptir. Ayrıca, bu havzadaki çökel serileri özellikle Kuvaterner'de oluşan buzul ve buzullar arası dönemlerdeki deniz seviyesi salınımlarından etkilenmiștir (Aksu vd., 1992a, b). Bunun yanı sıra bölgenin kara kesiminde Miyosen yaşlı taban kayayı üzerleyen Kuvaterner istiflerinin kalınlığının 1000 m civarında olduğu öne sürülmüştür (Schmidt, 1961).

$\mathrm{Bu}$ çalışmada, Türkiye Petrolleri Anonim Ortaklığı (TPAO)'ndan yasal izinle temin edilen kara ve deniz olmak üzere toplam 22 adet veri işlemi yapılmış analog sismik yansıma profili stratigrafik olarak yorumlanmıștır. Yorumlamalar sonucunda KilikyaAdana ve İskenderun Havzaları'nda Pliyo-Kuvaterner süresince biriken sedimanların dağılımlarının incelenmesi ile kalınlık ve derinlik haritalarının oluşturulması amaçlanmıştır.

\section{Bilimsel Yazın Taraması}

Doğu Akdeniz doğal yapısı gereği, uzun yıllar boyunca, temeli 1960'lı yıllara kadar dayanan akademik ve ekonomik amaçlara yönelik birçok jeolojik ve jeofiziksel araştırmaya konu olmuştur.

Woodside (1977), R.R.S. Shackleton'un 1972 ve 1974 yıllarındaki Doğu Akdeniz seferlerinde elde edilen batimetrik, gravimetrik ve sismik verileri yorumlayarak, Doğu Akdeniz'in tektonik unsurlarını ve kabuk yapısını açıklamaya çalışmıştır. Çalışmada, $500 \mathrm{~m}$ kontur aralıklı Pliyo-Kuvaterner sediman kalınlık haritası, Miyosen-Pliyosen sınırlı yansıtıcı yüzey derinlik haritası ve batimetri haritası çizilmiştir. Araştırmacı, sismik kayıtlarda Miyosen-Pliyosen çökellerin üst sınırı olarak yorumlanan ve sismik kayıtlarda reflektör A ile gösterilen, yüzeyin üzerinde uzanan Pliyosen-Kuvaterner yaşlı çökellerde ölçülen sismik hızların 1,5 ve $2,8 \mathrm{~km} / \mathrm{sn}$ aralığında değiștiğini belirlemiştir. Araştırmada, Pliyosen-Kuvaterner yaşlı çökellerin kalınlıklarındaki değişimin Doğu Akdeniz Havzasını farklı bölgelere ayırdığı açıklanmıştır.

Gökçen vd. (1991), R/V Koca Piri Reis'in 1988 ve 1989 yıllarındaki seferlerinde toplanan sismik yansıma verilerini değerlendirerek Alanya-Mersin klyı ötesi bölgesi Pliyo-Kuvaterner-Mesinyen izopak haritasını hazırlamıșlar ve harita üzerinde fayları ve kıvrımları göstermişlerdir. Araştırmacılar Alanya-Mersin kıyı ötesinin, Çukurova, Adana-Kilikya ve İskenderun olarak, üç alt bölgeye ayrıldığını açıklamışlardır.

Aksu vd. (1992a), R/V Koca Piri Reis'in 1988 ve 1990 seferlerinde toplanan sismik yansıma verilerini yorumlayarak kuzeydoğu Akdeniz'deki Adana, Kilikya ve İskenderun Havzalarının Kuvaterner çökelim kronolojisini incelemişlerdir. Çalışmada, kıta sahanlığının, aşınım uyumsuzlukları ile birbirlerinden ayrılan üst üste çökelmiş deltayik istiflerden meydana geldiği açıklanmıştır. Araştırmada Kilikya Havzası'nın çökme oranı 0,38 m/1000 yıl olarak hesaplanmıştır.

Aksu vd. (1992b), R/V Koca Piri Reis'in 1988 ve 1990 seferlerinde toplanan sismik yansıma verilerini tekrar yorumlayarak, kuzeydoğu Akdeniz'deki geç orojenik Kuvaterner havzaların oluşumunu incelemişlerdir. Çalışmada, Kilikya, İskenderun ve Lazkiye Havzalarındaki Kuvaterner çökellerinin birbirinden farklı deltayik istiflerden oluştuğu açıklanmıştır. Yaklaşık 620.000 yıl öncesinden günümüze değin delta ilerlemesini temsil eden 7 çökelim istifi yorumlanmıştır. Araştırmacılar, çökellerin kalınlık haritalarından 4 farklı kalın depolanma alanı önermişlerdir.

Walsh-Kennedy vd. (2014), R/V Koca Piri Reis'in 1991, 1992 ve 2008 seferlerinde toplanan sismik yansima verilerine ek olarak TPAO'nun mevcut verileri ile birlikte yorumlayarak, Kilikya Havzası boyunca karada da Adana Havzası'na kadar uzanan Geç Mesinyen ve Pliyo-Kuvaterner yaşlı çökellerin 
kuzeydoğu-güneybatı uzanımlı kalın bir lobunun bulunduğunu öne sürmüşlerdir.

\section{Materyal ve Yöntem}

Çalışma alanı içerisinde yer alan ve TPAO'dan yasal izinle temin edilen kara ve deniz olmak üzere toplam 22 adet veri işlemi yapılmış analog sismik yansıma profili yorumlanmıştır. TPAO ile yapılan gizlilik anlaşması gereği profillerin konum bilgisi verilemediğinden dolayı profillerin kapsama alanı Şekil 1'de gösterilmiştir. Sismik verilerin sismik stratigrafik yöntemle (Vail vd., 1977) yorumlanması ile Pliyo-Kuvaterner yaşlı sedimanları içeren çökel yüzeyi ve birim sınırı belirlenmiştir.

\section{1. Çalışma Alanının Batimetrisi}

Kuzeyde Adana Havzası, doğuda Misis-Girne Bindirme Kuşağı, güneyde Kıbrıs ve batıda Antalya Havzası (haritada gösterilmeyen) sinırlandırılan Kilikya Havzası'nın maksimum derinliği 1300 m'dir (Evans vd., 1978; Shaw ve Bush, 1978). Mulder vd. (1975)'e göre havza Kuzeydoğu Akdeniz kenarında denize doğru hafif bir eğimle uzanarak, $200 \mathrm{~m}$ derinlikte, genişliği yaklaşık 70 km'yi bulan, bir kıta sahanlığı oluşturmaktadır (Ergin vd., 1987). Bölgede yer alan ve yüksek debilere sahip olan Göksu, Seyhan ve Ceyhan nehirleri ve bu nehirlerin taşıdığı malzemelerin kıta sahanlığının genişliğinde etkin olduğu öne sürülmüştür (Ediger vd., 1999). Kilikya Havzası'ndan Misis-Girne Bindirme Kuşağı ile ayrılan İskenderun Havzası'nın en derin kısmı, yaklaşık $1000 \mathrm{~m}$ civarındadır. Bu derinlikteki, B-D ve KB-GD uzanımlı eş derinlik eğrileri İskenderun Havzası'nı Lazkiye Havzası'ndan ayırmaktadırlar. Havzada kıta sahanlığı 200 m'lik su derinliği ile sınırlandırılmış olup kıta yamacının alt sınırı $500 \mathrm{~m}$ su derinliği ile belirlenmiştir. Havzanın Amanos Dağları önünde uzanan kıta sahanlığı oldukça dardır. İskenderun Körfezi'nin en derin kısmı 80 m civarında olup körfez giriși 100 m'lik eş derinlik eğrisi ile sınırlandırılmıștır (Şekil 2).

Araştırma sahasının kara kesiminde, birbirlerinden Misis Dağları ile ayrılan Adana Havzası ve İskenderun Havzası'nın karasal uzantısı yer almaktadır. Kilikya Havzasının karasal uzantısı olarak kabul edilen Adana Havzası kuzeyde Toros Dağları ile sınırlandırılmıştır. Toros Dağları'nın kıyıdan birkaç kilometre içinde yüksekliği 3000 m ye kadar ulașabilmektedir. Göksu Deltası'ndan doğuya doğru gidildikçe Toros Dağları kuzey ve kuzey doğu yönlerinde kıyıdan bir yay şeklinde uzaklaşarak yerini Çukurova delta düzlüğüne bırakmaktadır. İskenderun Havzası'nın kara kesimi doğuda Amanos/Nur Dağları ile sınırlandırılmıştır.

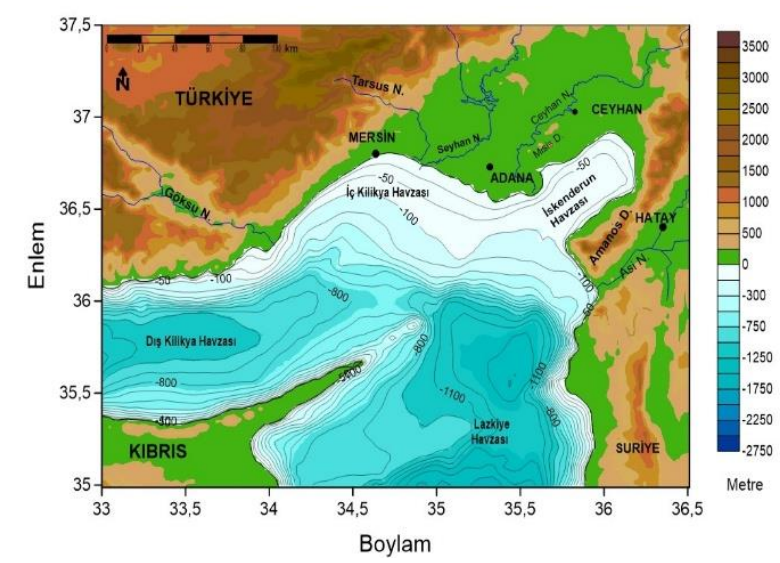

Şekil 2. Çalışma alanı ve çevresinin batimetrisi

\section{Araştırma Bulguları}

Pliyo-Kuvaterner yaşlı sedimanları içeren birim, çalışma sahası içerisinde stratigrafik olarak en genç birim olup üst yüzeyi, Kilikya Havzası ve İskenderun Havzası'nın denizel kesimlerinde deniz tabanını, İskenderun Havzası'nın karasal kesiminde ve Adana Havzası'nda günümüz topoğrafyasını temsil etmektedir. Birimin içerdiği sediman dağılımlarının incelenmesi için, sismik yansıma profilleri stratigrafik olarak yorumlanmış ve metre cinsinden kalınlık değerlerinin saptanabilmesi için literatürde (Aksu vd., 2005) yer alan birim hızı olarak 1700 m/sn kullanılmıştır.

Elde edilen Pliyo-Kuvaterner sediman dağllımı kalınlık haritası incelendiğinde (Şekil 3) kalınlık değerlerinin 0-2763 m arasında değiştiği görülmektedir. 


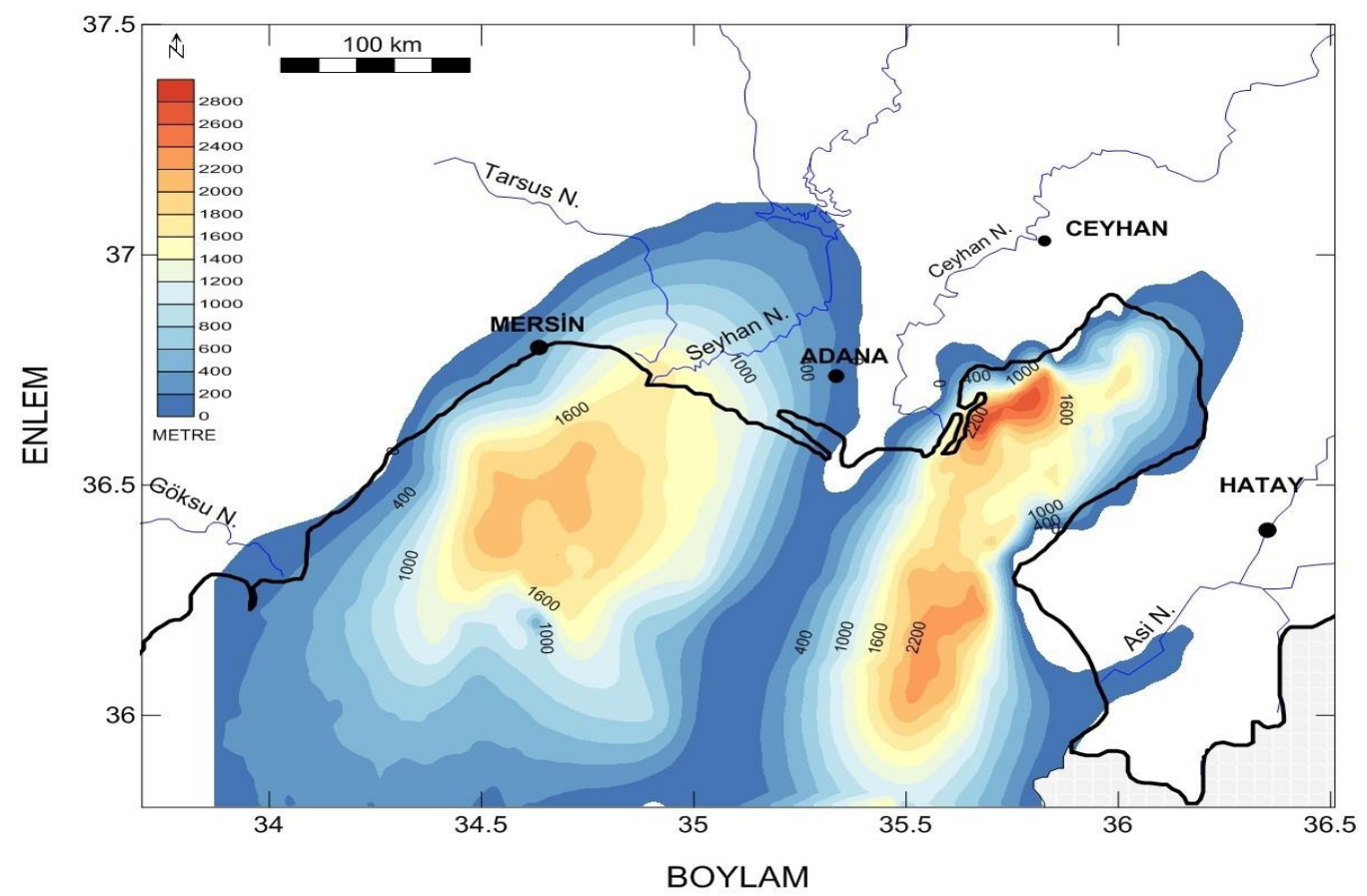

Şekil 3. Pliyo-Kuvaterner istifin kalınlık dağılımı

Kilikya Havzası'nda Pliyo-Kuvaterner istifin ulaștığı en yüksek kalınlık değeri $2050 \mathrm{~m}$ olup havzanın orta kesiminde yer almaktadır. Bu durum paleotopografik çukurluklarda biriken çökellerle açıklanabilmektedir. Çökellerin en yüksek kalınlığa ulaştı̆̆ı yerden "depolanma merkezi" uzaklaștıkça kalınlık değerleri azalmaya başlamaktadır. Özellikle de depolanma merkezinden KB'ye doğru gidildikçe, kilometre başına yaklaşı 31 metrelik bir azalma sonucu, Göksu Nehri ile Mersin arasında GB-KD yönlerinde uzanan kıyı bölgesine doğru, kalınlık 200 metreye düşmektedir. Toros Dağları'nın uzandığı bu kıyı bölgesi genellikle dar bir kıyısal düzlüğe sahip olup mevsimsel akarsuların etkisi altındadır. Dolayısı ile PliyoKuvaterner istifin kalınlığının azalması, denize sediman taşımının oldukça düşük olması ile açıklanabilmektedir. Bunun yanı sıra bölgede hakim olan hidrodinamik (dalga ve akıntı rejimi) koşulların etkisi de önem tașımaktadır. Pliyo-Kuvaterner istifin kalınlığı Göksu Nehri önlerinde 200-400 m civarında iken, Tarsus ve Seyhan nehirleri önlerinde 800-1600 m civarındadır. Bu durum Pliyo-Kuvaterner çökellerin depolanmasinda Tarsus ve Seyhan Nehirlerinin, Göksu Nehri'ne göre, oldukça etken olduğunu ifade etmektedir. Pliyo-Kuvaterner istifin kalınlığı Kilikya Havzası'nın güneyine, kıta yamacına doğru ilerledikçe 200 m'ye kadar düşmektedir. Kilikya ve İskenderun Havzalarında kita yamacının alt sınırının 500 m den başladığı düşünülürse (Ergin vd., 1987) buralar oldukça derin bölgelerdir.

Kilikya ve İskenderun Havzalarını ayıran GB-KD uzanımlı Misis-Girne Kuşağı'nın her iki yanında PliyoKuvaterner çökellerin kalınlığı 200 m'nin altında olup, kuşağın ekseni boyunca yer yer sıfıra düşmektedir.
Bunun nedeni olarak güçlü dip akıntılarının, depolanmadan çok, sediman taşınımına yol açması gösterilebilmektedir.

Kilikya Havzası'nın karasal uzantısı niteliğindeki Adana Havzası'nda Pliyo-Kuvaterner istifin kalınlığı 01600 m olarak değişmektedir. Toros Dağları ile Misis Dağı eteklerinde Pliyo-Kuvaterner istif yok denecek kadar azdır. Bu havzada istifin en yüksek kalınlık değerlerine, 1000-1600 m, Tarsus ve Seyhan nehirlerinin G-GB yönlerinde birbirlerine doğru yaklaştıkları alanda karşılaşılmıștır.

İskenderun Havzası'nın denizel kesiminde, MisisGirne Yükselimi ve Amanos Dağı açıklarında, PliyoKuvaterner istifin kalınlığı 200 m'den daha fazladır. Havzada Asi Nehri açığı ve Yumurtalık önlerinde Pliyo-Kuvaterner istifin kalınlık değerleri sırasıyla 2250 ve 2763 m'ye ulașmaktadır. Bu yüksek kalınlık değerlerinin paleotopografik çukurluklarda biriken çökellerle ile ilintili olduğu düşünülmektedir. Bunun yanı sıra, Yumurtalık önlerindeki Pliyo-Kuvaterner istifin en yüksek kalınlık değerine ulaşması, Ceyhan Nehri'nin taşıdığı sedimanların burada depolanması ile açıklanabilmektedir.

KB'da Misis Dă̆ı, G-GD' da Amanos Dağları ile sınırlanan İskenderun Havzası'nın karasal kesiminde Pliyo-Kuvaterner istife rastlanılmamıştır (Şekil 3).

Pliyo-Kuvaterner istifin taban topografyası (Paleotopografya) haritası su derinliği değerlerinin sismik kesitlerden elde edilen kalınlık değerlerine eklenmesi ile oluşturulmuştur (Şekil 4). 


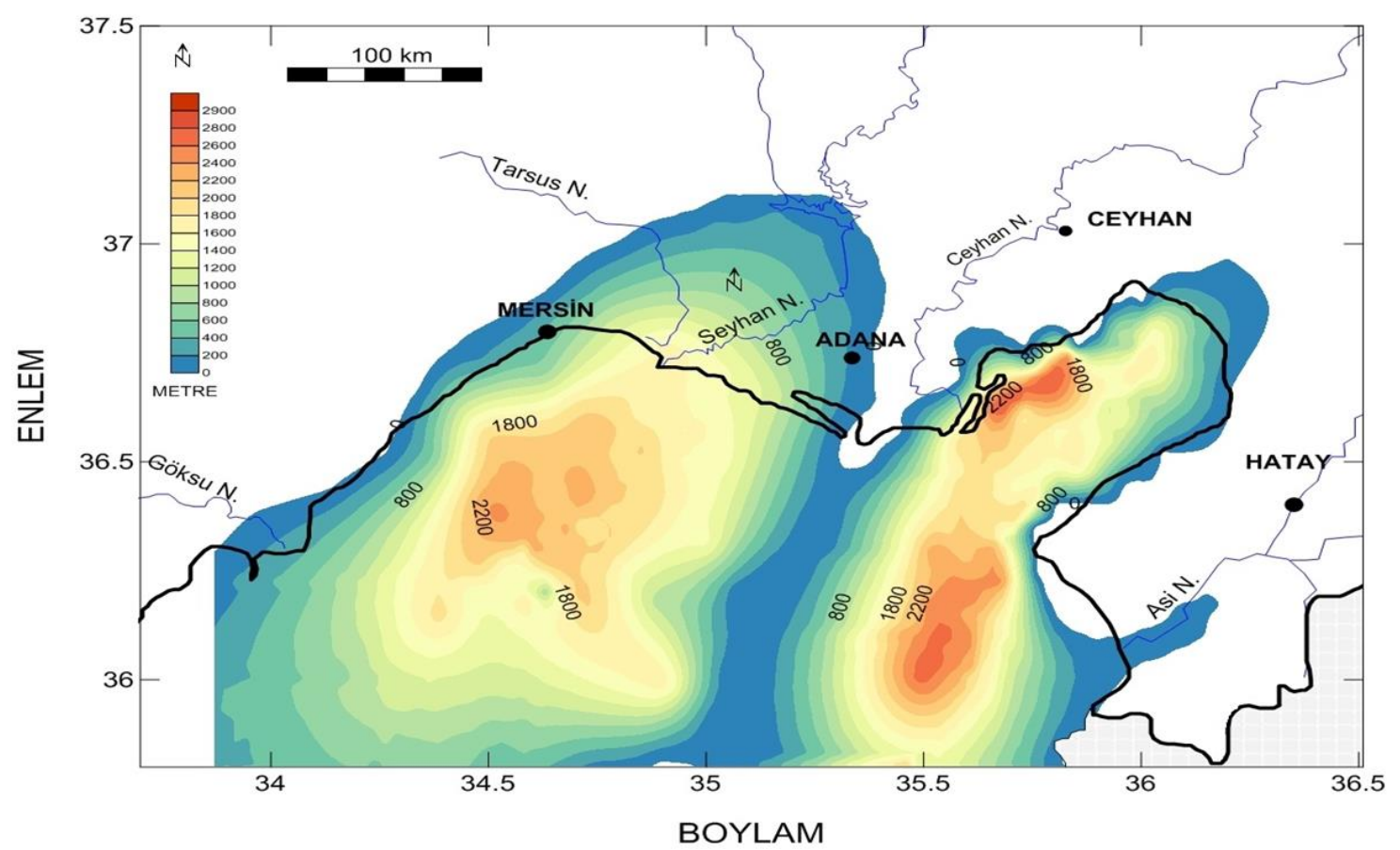

Şekil 4. Pliyo-Kuvaterner istifin paleobatimetrisi

Pliyo-Kuvaterner istifin paleotopografyasında dikkat çeken en önemli özellik, bir tanesi Kilikya Havzası'nda iki tanesi de İskenderun Havzası'nın denizel kesiminde yer alan çukurluklardır. Kilikya Havzası'ndaki çukurluğun en derin noktası $2400 \mathrm{~m}$ olarak ölçülmüştür. Bu çukurluğun uzun ekseni GBKD yönünde uzanmaktadır. İskenderun Havzası'nın denizel kesimindeki çukurluklardan bir tanesi Yumurtallk önlerinde yer almakta olup en derin noktası 2793 m dir. Bu çukurluğun da uzun ekseni G$\mathrm{K}$ yönlerinde uzanmaktadır. Sismik kayıtların incelenmesi ile bu yapıların şekillenmesinde faylanmanın yanı sıra tuz tektoniğinin de etkili olabileceği yorumuna varılmıştır.

\section{Sonuç ve Tartışma}

Pliyo-Kuvaterner çökellerin kalınlık değerlerinin 02763 m arasında değiștiği belirlenmiștir. En yüksek kalınlık değerleri İskenderun Havzası'nın denizel kesiminde, Asi Nehri açıklarında 2250 m, Yumurtalık önlerinde 2763 m, Kilikya Havzası'nın orta kesiminde 2050 m olarak ölçülmüştür. Misis-Girne Yükselimi'nin her iki yanında çökel kalınlığının $200 \mathrm{~m}$ den az olduğu ve yükselimin ekseni boyunca sıfıra düştüğü gözlemlenmiştir. Adana Havzası'nda Pliyo-Kuvaterner sediman kalınlığı 0-1600 m arasında değişmektedir, Tarsus ve Seyhan Nehirlerinin birbirlerine yaklaștıkları kıyı kesiminde kalınlık değeri 1600 m ile en yüksek değere ulaşmaktadır.

Pliyo-Kuvaterner istifin paleotopografya haritasında göze çarpan en önemli özellik, bir tanesi Kilikya Havzası'nda $2400 \mathrm{~m}$ derinlikte, diğer iki tanesi de İskenderun Havzası'nın denizel kesiminde 2700 ve $2793 \mathrm{~m}$ derinliklerde yer alan çukurluklardır. Bu çukurlukların oluşumunda faylanma ile tuz tektoniğinin etkili olduğu düşünülmektedir.

\section{Teşekkür}

$\mathrm{Bu}$ çalışma Süleyman Demirel Üniversitesi Bilimsel Araştırma Projeleri Koordinasyon Birimi tarafından 4386-D1-15 nolu proje kapsamında desteklenmiștir.

Ayrıca makalenin değerlendirmesi aşamasında yer alan hakemlere yapıcı eleştirileri ve değerli katkıları için ve Türkiye Petrolleri Anonim Ortaklığı'na veri desteği için teșekkür ederiz.

\section{Conflict of Interest / Çıkar Çatışması}

Yazarlar tarafından herhangi bir çıkar çatışması beyan edilmemiștir.

No conflict of interest was declared by the authors.

\section{Kaynaklar}

Aksu, A.E., Uluğ, A., Piper, D.J.W., Konuk, T., Turgut, S., 1992a. Quaternary Sedimentary History of Adana, Cilicia and Iskenderun Basins, Northeast Mediterranean Sea. Marine Geology, 104, 55-71.

Aksu, A.E., Calon, T.J., Piper, D.J.W., Turgut, S., Izdar, E.K., 1992b. Architecture of Late Orogenic Basins in the Eastern Mediterranean Sea. Tectonophysics, 210, 191-213.

Aksu, A., Calon, T., Hall, J., Mansfield, S., Yaşar, D., 2005. The Cilicia-Adana Basin Complex, Eastern Mediterranean: Neogene Evolution of an Active 
Fore-Arc Basin in an Obliquely Convergent Margin. Marine Geology, 221, 121-159.

Dewey, J. F., Hempton, M.R., Kidd, W. S. F., Şaroğlu, F., Șengör, A.M.C., 1986. Shortening of Continental Lithosphere: the Neo-Tectonics of Eastern Anatolia. A Young Collision Zone. In: Coward, M.P., Ries, A.C. (Eds.), Collision Tectonics. Geological Society Special Publication, 19, 3-36.

Ediger, V., Okyar, M., Tekiroğlu, E.S., Görür, N., Çağatay, N., 1999. Kilikya-Adana Havzası Kıta Sahanlığı Geç Kuvaterner Çökellerinin Araştırılması. TÜBİTAK Rapor No: YDABÇAG-599/G, 86s.

Ergin, M., Alavi, S.N., Bodur, M.N., Ediger, V. Okyar, M., 1987. Kuzeydoğu Akdenizin Jeofiziği, Stratigrafisi ve Jeokimyasına Genel Bir Bakıș. Orta Doğu Teknik Üniversitesi, Deniz Bilimteri Enstitüsü, Erdemli, İçel, 110s

Ergün, M., Oral, E.Z., Çifçi, G., 1995. Doğu Akdeniz'in Yapısı ve Levha Tektoniğindeki Yeri. Jeofizik, 9(10), 71-78.

Evans, G., Morgan, P., Evans, W.A., Evans, Woodside, J.M., 1978. Faulting and Halokinetics in the Northeastern Mediterranean between Cyprus and Turkey. Geology, 6, 392-396.

Gökçen, S.L., Kelling, G., Uluğ, A., Gökçen, N., Özel, E., 1991. Alanya Mersin Arasındaki Denizel Bölgedeki Genç Tektonik Yapılar. Jeofizik, 5, 3-12.

Mulder, C.J., Lehner, P., Allen, D.C.K., 1975. Structural Evolution of the Neogene Salt Basins in the Eastern Mediterranean and the Red Sea. Geology, 54, 208221.

Robertson, A.H.F., Dixon, J.E., 1984. Introduction: Aspects of the Geological Evolution of the Eastern Mediterranean. In: Dixon, J.E., Robertson, A.H.F. (Eds.), The Geological Evolution of the Eastern Mediterranean (1-74). Special PublicationGeological Society of London, 824s, London.

Robertson, A.H.F., Clift, P.D., Degnan, P., Jones, G., 1991. Paleogeographic and Paleotectonic Evolution of the Eastern Mediterranean Neotethys. Palaeogeography, Palaeoclimatology, Palaeoecology, 87, 289- 344.

Schmidt, G. C., 1961. Stratigraphic Nomenclature For he Adana Region Petroleum District VII. Petroleum Administration Bulletin, 6, 47-63.

Shaw, H.F., Bush, P.R. 1978. The Rnineralogy and Geochemistry of the Recent Surface Sediments of the Cilicia Basin, NE-Mediterranean. Marine Geology, 27, 115-136.
Vail, P.R., Mitchum, R.M., Thompson III, S., 1977. Seismic Stratigraphy and Global Changes of Sea Level, Part 4: Global Cycles of Relative Changes of Sea Level. In Payton, C.E. (Ed.), Seismic Stratigraphy Applications to Hydrocarbon Exploration (83-97). American Association of Petroleum Geologists Memoir 26, 516p, Tulsa, Oklahoma.

Walsh-Kennedy, S., Aksu A.E., Hall J., Hiscott, R.N., Yaltırak, C., Çifçi, G., 2014. Source to Sink: The Development of the Latest Messinian to PlioceneQuaternary Cilicia and Adana Basins and Their Linkages with the Onland Mut Basin, Eastern Mediterranean. Tectonophysics, 622, 1-21.

Woodside, J.M., 1977. Tectonic Elements and Crust of the Eastern Mediterranean Sca. Marine Geophysical Researches, 3, 317-354. 